\title{
Healthcare Organizations and Enterprise Architecture: A Case Study in Canada
}

\author{
Samuel Tallé Fogang (DBA) \\ Onyeka Uche Ofili (PhD) \\ International School of Management, Paris
}

Doi:10.19044/esj.2021.v17n8p33

Submitted: 26 November 2020

Accepted: 05 March 2021

Published: 31 March 2021

\author{
Copyright 2021 Author(s) \\ Under Creative Commons BY-NC-ND \\ 4.0 OPEN \\ ACCES
}

Cite As:

Fogang, TF. \& Ofili UO. (2021). Healthcare Organizations: A Case Study in Canada European Scientific Journal, ESJ, 17(8), 33. https://doi.org/10.19044/esj.2021.v17n8p33

\begin{abstract}
:
The paper focuses on exploring the perceptions of stakeholders (medical doctors, nurses, pharmacists, IT staff and other employees) in healthcare organizations in Canada on how they developed Enterprise Architecture (EA) to improve managerial decision making and align business activities and Information Technology (IT). Both quantitative and qualitative methods were adopted for this research. A total of 120 questionnaires were sent out but only 72 responses were received. Participants included industry professionals involved in implementing information systems (IS) within healthcare organizations. Data was collected physically and through emails. Also 3 subject matter experts (experts) were interviewed for the study. These experts each have over ten years' experience in EA practice and are doctorate degree holders (PhDs). The results of the study showed that stakeholders see the potential for EA to be a tool for planning IT/IS projects, breaking down organizational silos, creating digital transformation, and proactively responding to disruptive forces. They do not see EA as the necessary tool for integrating IT solutions.
\end{abstract}


Keywords: Enterprise Architecture (EA), Enterprise Architecture Management (EAM), Information System (IS), Information Technology (IT), Healthcare Organizations

\section{Instroduction:}

Enterprise Architecture (EA) is a practice and emerging field that aims to improve the management and functioning of complex healthcare enterprises and their information systems (IS) (Saint-Louis et al., 2019). Its purpose is to ensure successful business structures or business-IT alignment and manage required organizational transformation (Gerber et al., 2020). The field of EA has the potential to offer significant insights and technologies to help organizations address the "Grand Challenges" of the future (Ilin et al., 2018). EA fundamentally adopts a systems perspective to describe the essential elements of a socio-technical organization and their relationships to each other and to the environment in order to understand complexity and manage change (Gerber et al., 2020). EA modelling has become decisive to achieve models that accurately represent behaviour and assets of companies and lead them to make appropriate business decisions (Pérez-Castillo et al., 2020). The main goals of EA adoption in healthcare organizations are to achieve: (1) interoperability through standardisation, consolidation and effective management of complexities; (2) governance and (3) business and IT strategy alignment (Jonnagaddala et al., 2020). However, even in countries with advanced levels of healthcare practice supported by electronic processes and communication (eHealth), there are interoperability challenges because of different models of governance adopted by the organizations (Saripalle, 2019).

Many healthcare organizations have attempted to deal with their ensuing organizational complexity by adopting industry-recognized practices such as EA. Although it may not be very straightforward on how EA will help healthcare enterprises face realities of the future, there are some suggestions as to how this can be achieved (Masuda et al., 2021). EA can be a practical tool to increase the management power on IT of any organization, and there is a weakness in designing qualitative models of EA and qualitative metrics of EA (Timm et al., 2017). Some of the criticism against EA management (EAM) is that it requires a lot of effort (Kotusev, 2018) and that the benefits thereof are not directly measurable and are realized with some time lag (Plessius et al., 2018). It is difficult to discover or formulate special Critical Success Factors (CSFs) for adopting the EA metamodel in the health sector (Júnior et al., 2020).

The purpose of this multiple case study is to explore the perceptions of stakeholders (medical doctors, nurses, pharmacists, IT staff and other 
employees) in a healthcare organization in Canada on how they developed their own model of EA to improve managerial decision making, and align business activities and IT within the enterprise. The specific objective of the study is to build an effective model of EA for a healthcare organization in Canada that really meets its strategic vision and improves its productivity. Basically, there are two main questions in this research:

RQ1: What are the perceptions of stakeholders in a healthcare organization in Canada on how they developed their own model of EA to improve managerial decision making?

RQ2: What are the perceptions of stakeholders in a healthcare organization in Canada on how they developed their own model of EA to align business activities and IT within the enterprise?

The findings of this study will be of benefit to society considering that EA plays an important role in healthcare organizations and helps to improve services provided to patients. The study will also show how healthcare centers should be organized in terms of business architecture, IS architecture, and technology architecture in order to deliver the best quality of services to people. Furthermore, this research will contribute to understanding the most common mistakes the managers of healthcare organizations make in their strategic decisions when investing in IS and technology. As healthcare delivery is a huge item of expenditure by governments around the world (Mcintyre et al., 2017), the findings of this study will contribute to identifying key cost optimization factors in IT delivery in healthcare organizations. It will also provide a customized approach to manage integration of IT systems and their interoperability within healthcare organizations.

\section{Literature Review}

This section consists of a literature review of Enterprise Architecture as it is viewed and applied through diverse aspects of organization management. Based on scholarly papers, it includes the current knowledge, substantive findings, as well as theoretical and methodological contributions from scholars related to the concept of Enterprise Architecture. The literature review section is divided into six sub-sections, namely: 1) Enterprise Architecture and Healthcare Organizational Complexity, 2) Enterprise Architecture and Business Strategy, 3) Enterprise Architecture and IS/IT Management, 4) Enterprise Architecture and Corporate Governance, 5) Enterprise Architecture and performance management, 6) Enterprise Architecture and Business Process management. 


\section{Enterprise Architecture and Healthcare Organizational Complexity}

This sub-section of the literature review described organizations through their components that make them more complex over time. It pointed out multiple dimensions and key factors that characterize organizations and how they affect the level of complexity (Ridgely et al., 2019; Tsoukas, 2017; Kernick, 2018). The management of organization requires a systemic and holistic approach, considering all factors (internal and external) influencing the functioning of the organizations. Some studies, including Ridgely et al. (2019), paid particular attention to such complexity as it affects healthcare organizations. The sensitivity of the sector brings more complexity in managing the healthcare organizations than any other business sector. Indeed, healthcare organizations are highly specialized and have a multiple division of services leading to complexity. Scholars and researchers such as Patri and Suresh (2017), Bokhour et al. (2018), and Wager et al. (2017) conducted research studies whose results clearly demonstrated the deep complexity of healthcare organizations. Therefore, these authors pointed out the following factors that characterize the complexity of such a sector: IS, Processes management, a lack of leadership and clear goal, organization size, bureaucratic rules, priority definition, a lack of holistic approach in management, interactions between various stakeholders internal \& external (patients and providers, providers and others providers, providers and insurers suppliers and providers). The high degree of division of labor and specialization in healthcare are grounds IS appeared frequently as one of the critical components complexifying healthcare organizations. Although a lot of effort and money have been spent to support IS within organizations, it remains that the results are still so far below what are expected.

In other to overcome organizational complexity as it affects IS, some studies recommends that healthcare organizations should have the following; interoperable IS (Leal, Guédria, \& Panetto, 2019); competent human resources, support and commitment from top management (Hernandez et al., 2018); develop a framework allowing the interconnection of entities and actors to work with a right integrated IS (Guha, \& Kumar, 2018); motivation of stakeholders involved in developing IS and a framework for managing the implementation of IS projects (Hwabamungu et al., 2018). In fact, as Alotaibi and Liu (2017) mentioned, there are, sometimes, misalignment between relevant business requirements content and IS architectural solution, thereby lowering its quality. In that case, finding ways to align IS with organization objectives and strategies remains a solution to address the complexity of organizations (Alotaibi \& Liu, 2017). 
Researchers such as Saint-Louis et al. ( 2019); Dang and Pekkola (2017); Foorthuis et al. (2020); Banaeianjahromi and Smolander (2019); and Szabó and Öri (2017) led studies whose findings showed the importance of EA in supporting organizations in addressing complexity if EA is involved in the process of managing organization. These scholars established that organizations must develop models of EA frameworks in line with their business context to gain the maximum benefit of EA as a tool for addressing complexity. In effect, EA provides organizations with holistic specification about the strategy, key activities, information and organizational technologies, and functions and their effects on business processes (Timm et al., 2017).

\section{EA and Business Strategy}

This sub-section of the literature review is focused on the concept of business strategy and its importance towards having a successful business. It also addressed the point of using EA for supporting business strategy in organizations in general (Kitsios \& Kamariotou, 2019; Bhattacharya, 2018) with a special focus on healthcare organizations. It begins by identifying the origin of the strategy concept, which was demonstrated by some researchers such as Paley (2019) and McKiernan (2017). The origin of strategy is also far more than the origin of competition. Strategy began because of the competitive environment. Competition precedes strategy. As the competition exists within an environment, actors operating in that environment develop strategies to take advantages over competitors. Researchers such as Latham (2017) highlighted how strategy is fundamental for any organization. Strategy helps the organization to define how business will be conducted and proactively act on levers that will help organization to take advantage over its competitors and for sustainable development.

As much as strategy is important to the survival of organizations, implementing a robust strategy within organizations remains a challenging process. Challenges of implementing strategy in organizations have been highlighted by Kabeyi (2019) and Rani (2019). Among the challenges facing organizations for implementing strategy, the authors revealed the lack of communication, the lack of understanding for overall aims and direction, and the lack of support. They also pointed out inadequate funding, untimely disbursement of resources, staff resistance to change, and lack of skills for those in charge to implement the strategy. Healthcare sector, in addition to the prior challenges, has other specific challenges in implementing strategy as pointed out by Obeidat et al. (2017) and Pickup et al. (2018). Those challenges are related to national policies and a health system adapted to 
context. They also noted the rigidity of guidelines, the high turnover of human resources, and the lack of competencies among health workers.

Prior researches have been conducted to find solutions to overcome challenges in implementing strategy and the added value of EA in supporting the definition and implementation of strategy. Greer et al. (2017) and Kitsios and Kamariotou (2017) have put emphasis on leadership, transparency, and the development of IS as support for implementing strategy. They also pointed out the fact that organizations should rethink the framework of defining and implementing business strategy considering the reality of the environment based on the influence of new IS on strategy. EA can be a vital means to align the required changes in corporate strategy and business processes with an increasingly complex IT landscape. EA helps to have a holistic approach and help managers to transform the strategy from perspective theory to implementation. In essence, EA helps to understand and deliver corporate objectives and business requirements and to communicate and develop solutions for the institution across the entire institution.

\section{EA and IS/IT Management}

This sub-section is essentially focused on IS within organizations and the support of EA in the ecosystem of digital transformation of organizations (Kasemsap, 2018; Banaeianjahromi \& Smolander, 2019; Gampfer et al., 2018). Information system is an integrated set of components for collecting, storing, and processing data and for providing information, knowledge, and digital products (Zwass, 2020). As cited by Laudon and Laudon (2020, p. 48 ) and recalled by Knauer et al. (2020), IS is also defined as "a set of interrelated components that collect (or retrieve), process, store, and distribute information to support decision making and control in an organization". IS is distinct from IT. In contrast to IS, IT involves hardware, software, services, and supporting infrastructure to manage and deliver information. It involves any technology that can be used to manipulate information, whereas IS focuses primarily on information and all of the equipment, processes, and people involved in the dissemination of information within an organization. The importance of IS and IT within organizations cannot be overemphasized. Various studies including Gorkhali and $\mathrm{Xu}$ (2017); Kasemsap (2018); Aceto et al. (2018); and Ross and Venkatesh (2016) demonstrated how important both concepts are for organizations today and in the future. They all agree that organizations today rely heavily on IS as it participates in the performance and the competitiveness of organizations. IS also helps to increase legibility, reduce medical errors, shrink costs, and boost the overall quality of healthcare (Aceto et al., 2018; Ahmadi et al., 2017; Esfahani et al., 2018). 
IS in organisation must be well managed to provide expected results. Harlie et al. (2019) and Sanchez and Terlizzi (2017) published articles showing that the success of an IS depends on how it is managed. However, managing IS involves many constraints that often lead to failure of implementing IS, hence producing important consequences. Islam, Poly, and Li (2018); Lagsten and Andersson (2018); Neto et al. (2017); and See et al. (2018) published articles which addressed challenges related to IS in organization, and more precisely in healthcare organizations. Among the challenges, they revealed the end-user's resistance to change, the complexity of the environment, the poor managerial practice because of lack of training, and lack of a robust analysis. As solutions to overcome those challenges and help to improve the management of IS, Olsen (2017), Sligo et al. (2017), and Müller and Buchkremer (2018) revealed the capabilities of leveraging EA within organizations. According to these authors, EA provides standards and framework which foster success in IS Management. It helps to educate stakeholders and show to business owners and decision makers the role and nature of information as a resource in the organization. Although they agree on the potential of EA to address challenges of managing IS, some of them highlighted the challenges related to implementation of EA itself (Olsen, 2017; Lauvrak et al., 2017; Banaeianjahromi \& Smolander, 2019).

\section{EA and Corporate Governance}

This subsection focused on the concept of governance in organizations and its derivative elements (corporate governance, international governance, national governance and local governance, and IT governance) as they are applied and used by actors in organizations (Abunadi, 2019; Tanaka et al., 2018; Rahimi et al., 2017; Du Plessis et al., 2018). The concept originated from the need for countries to have a framework including the norms, values, and rules of the game for managing public affairs with transparency and objectivity, and including the participation of all actors. Some researchers have devoted time not only to define the particularity of corporate governance but also to see what makes it different from other derivative terms of governance and its importance in the context of business management (Andrew MacDougall et al., 2017; Shanks et al., 2018; Pillai \& Al-Malkawi, 2018). Corporate governance has a direct impact on business performance and drives business strategy.

The importance of corporate governance is translated by its capability to provide a business environment that does not suffer from any contestation, and a business environment that offers a certain credibility to stakeholders and shareholders. All organizations including healthcare organizations must develop a culture of corporate governance. This is particularly important as organizations are facing more competitiveness today than ever before because of globalization and new technologies. Some studies also revealed 
the relationship between corporate governance and business management (Madhani, 2017; Saidat et al., 2019; Herdjiono \& Sari, 2017). Governance defines management, and the concepts of management cannot be applied without governance. Studies by Lipunga et al. (2019) and Reddy et al. (2020) also put an emphasis on the governance of healthcare organizations, highlighting the fundamental relationship between corporate governance and the performance of healthcare organizations. According to the authors, having good governance helps to deliver health services with efficiency irrespective of the size of the healthcare organization and the resources allocated. The success of healthcare organizations depends on a governance framework developed by decision makers.

Technology represents an important part of corporate governance. In fact, the functioning of organizations today highly depends on technology and IS. Hence, corporate governance cannot be separated from technology and IS. Some researchers also highlighted the importance of IT governance and the effort and resources spent by organizations (including healthcare organizations) to sustain it (Nugroho, 2017; Juiz et al., 2017). As Corporate governance and IT governance are very useful for organizations, some studies have identified EA as an essential instrument for supporting governance (Kotusev, 2017; Shanks et al., 2018). EA complements Business Rule Management and IT governance. EA brings an efficient framework for supporting governance and delivers the necessary information for a sustainable governance.

\section{EA and Performance Management}

This subsection focused on performance management within organizations, including healthcare organizations, and how performance management can be approached from EA's point of view (Hazen et al., 2017; Ahlemann et al., 2021). It pointed out the fact that performance within organizations involves the comparison between two aspects (objective against realization). Performance management consists of evaluating what was supposed to be achieved compared to what has been achieved (Aguinis, 2019; Ashdown, 2018; Dimitropoulos, 2017). There are various synonyms of performance management; organizational effectiveness, organizational efficiency, and organizational alignment. Studies have established the correlation between performance management and the growth, effectiveness, and efficiency of an organization (Smith \& Bititci, 2017; Sardo \& Serrasqueiro, 2017; Saridakis et al., 2017).

Adopting an EA framework will help organizations to develop the performance management initiatives that are in line with the business objectives and strategy (Shanks et al., 2018; Jusuf \& Kurnia, 2017). EA is an 
instrument that has the real potential to improve performance within organizations and help to achieve better results from IS. EA helps to cover necessary aspects of business performance involving the responsibility for IT investments, the leverage of time as a value, the long term alignment that will help to maintain a good trend of performance, the coordination of investments in IS with changes in business processes, avoiding to spend money to systems that do not provide real value or return on investment to the company.

\section{EA and Business Process Management}

This part of the literature review detailed the concept of the business process within organizations and how important it is when taking a systemic approach to manage organizations in the right way. There is alignment between the business process and other components within organizations such as IS/IT assets, business objectives, business strategy, and so on. The management of business processes cannot be separated from the other elements of the organization. A systemic approach of management is needed in order to align and perform business processes and get expected results. So, companies need to have a tool or an instrument that fosters this kind of management and a holistic view of the organization.

In the context of organization, technologies exist for supporting processes. In addition, some researchers argue that the Business Process Management (BPM) is a concept used to establish the link between IT and business processes and the healthcare sector is no exception (Laurenza et al., 2018; Lombardi, 2019). The healthcare business processes are very critical as they are related to human lives. It is therefore imperative to define the best way for managing, improving efficiency and aligning the processes with not only technology but also with other components that constitute the whole organization.

\section{Research Methodology}

The research design involved the utilization of both quantitative and qualitative research methods in addressing the research questions. The methodology entailed examination of the perceptions of participants who had been actors in the development of IS within healthcare organizations or had been using technologies in their daily work within their respective organizations. The mixed methods research was appropriate because it allowed us to better understand the perceptions of the researcher participants by comparing the questionnaire responses to the opinion of subject matter experts. The mixed method brings the advantage of helping to minimize errors that may occur as a result of using only the qualitative or quantitative 
method while maximizing the advantages of each method (Almeida, 2018). The qualitative dimension of the methodology was appropriate because, as Hammarberg et al. (2016) noted, "qualitative methods are used to answer questions about experience, meaning and perspective, most often from the standpoint of the participant". Quantitative research, on the other hand, deals with data that are numerical or that can be converted into numbers (Sheard, 2018). This data can subsequently be summarized and analyzed using mathematical operations (Walliman, 2017) and further presented in ways that are both clear and persuasive.

By exploring the perceptions of individuals who have had experiences with IS and technology projects within healthcare centers, it was possible to obtain "multiple perspectives" that further our understanding of EA as perceived within healthcare organizations. Each individual identifies certain characteristics and attributes in a given situation. This study was designed to gain an understanding of these variations in the interpretation of EA.

Qualitative researchers have made significant contributions to health services and policy (HSP) research (Chafe, 2017). Qualitative research is particularly appropriate when the objective is to determine the meaning of a phenomenon through description and to develop concepts that help in the understanding of natural phenomena with an emphasis on the experiences, meaning, and views of the participant (Bradshaw et al., 2017; Aspers \& Corte, 2019). The research question (see appendix 1 below for the questionnaire used for the research) for this study centered on the perceptions of stakeholders in healthcare organizations in Canada on models of EA to improve managerial decision making and their own model to align business activities and IT within the enterprise.

\section{Methodology in Brief}

Table below summarizes the main steps we followed:

\begin{tabular}{|c|c|}
\hline o & Tasks \\
\hline & Defined $\mathbf{6}$ research statements to be tested \\
\hline & $\begin{array}{l}\text { Set-up a Questionnaire with } 21 \text { logical questions } \\
(2 \text { optional questions \& } 19 \text { mandatory questions })\end{array}$ \\
\hline $\begin{array}{l}\text { Tested content of questionnaire by meeting } 2 \text { healthcare } \\
\text { professionals }\end{array}$ \\
$\begin{array}{c}\text { Adjusted questionnaire based on the remarks and feedback of } \\
\text { the } 2 \text { healthcare professionals }\end{array}$ \\
\hline
\end{tabular}




\begin{tabular}{|c|c|}
\hline & $\begin{array}{l}\text { Sent out the questionnaire to } 100+\text { professionals in over } 30 \\
\text { different healthcare organizations in Canada. The simple random } \\
\text { sampling approach was adopted. }\end{array}$ \\
\hline & $\begin{array}{l}\text { Obtained consent of study participants and ensured data privacy } \\
\text { and confidentiality }\end{array}$ \\
\hline & $\begin{array}{l}72 \text { participants responded to the questionnaire. Based on the } \\
\text { research topic, population, aim of this research and analysis } \\
\text { techniques adopted for this research, the researchers believe that the } \\
\text { sample size used for this study is appropriate (Rahi, 2017). }\end{array}$ \\
\hline & $\begin{array}{l}\text { Compiled all response data in a single Excel file and analyzed it } \\
\text { by using statistical tool ( } \mathrm{R} \text { software) }\end{array}$ \\
\hline & Matched Research statements with related questions \\
\hline 0 & Analyzed questionnaire responses \\
\hline 1 & $\begin{array}{l}\text { Interviewed } 3 \text { Experts with background in EA. The experts were } \\
\text { carefully selected, using purposive sampling approach, as they have } \\
\text { extensive knowledge of the subject of EA. The selection of the } 3 \\
\text { experts is appropriate in terms of size as it gives the researchers } \\
\text { enough time to conduct in-depth interview with the participants. } \\
\text { Hence, there is a clear rationale for this and it fulfilled specific } \\
\text { purpose with respect to the research questions (Cleary et al., 2014). }\end{array}$ \\
\hline 2 & $\begin{array}{l}\text { Compared the outcome of questionnaire responses with Experts' } \\
\text { opinion }\end{array}$ \\
\hline
\end{tabular}

\section{Data Analysis and Findings}

The tool used for analyzing data is R software, which is a statistical tool, supporting both quantitative and qualitative data analysis. Questionnaire responses were transformed into a dataset and ingested into the $\mathrm{R}$ environment. To facilitate data ingestion into the software environment and for a better processing of the data, header of dataset, which corresponds to specific questions, has been coded as $Q x$ (with x taking a value from 1 to 20) as follows, and aligned with the configuration of the questionnaire:

Q1: Name of your organization (optional)

Q2: Name of respondent (optional)

Q3: College degree or certification in IT/IS area

Q4: Years of Experience in healthcare: $(0-2,3-6,6-10,11$ or more.) 
Q5: Years of Experience with IT/IS projects: $0-2 \quad 3-6 \quad 6-10 \quad 11$ or more.

Q6: EA should be used as a tool of planning in IT/IS projects.

Q7: A primary goal of EA in IT/IS projects is to improve the wellbeing of the patient population.

Q8: A primary goal of EA in IT/IS projects is to improve the outcomes from the use of technology.

Q9: A primary goal of EA in IT/IS projects is to reduce the costs of healthcare activities.

Q10: IT/IS projects supporting the treatment of critical diseases, such as cancer, should have a higher priority than projects to support simple injuries.

Q11: Each IT/IS project in EA document should demonstrate its integration with other existing solutions.

Q12: An IT/IS project with no interaction on existing solutions should be excluded in an EA document.

Q13: An IT/IS project with interactions on existing solutions should be included in EA document even if it has a limited impact on service quality.

Q14: EA is a tool that can help break down administrative silos within an organization.

Q15: EA is a tool that can help create synergy between managers of different departments in an organization.

Q16: EA encourages department heads to compete intensely to be the owners of business processes in IT/IS projects.

Q17: Stakeholders without IT/IS background often do not support EA in IT/IS projects.

Q18: EA should identify and analyze the execution of change toward desired business vision and outcomes.

Q19: EA delivers value by presenting business and IT leaders with signature-ready recommendations for adjusting policies and projects to achieve target business outcomes.

Q20: Stakeholders with IT/IS background often encourage EA in IT/IS projects.

As each column represents a variable of dataset, the approach was to analyze each variable at a time (univariate analysis), and then the correlation between variables (multivariate analysis). The picture below is for setting the software work environment, installing libraries, and loading the dataset for analysis. 


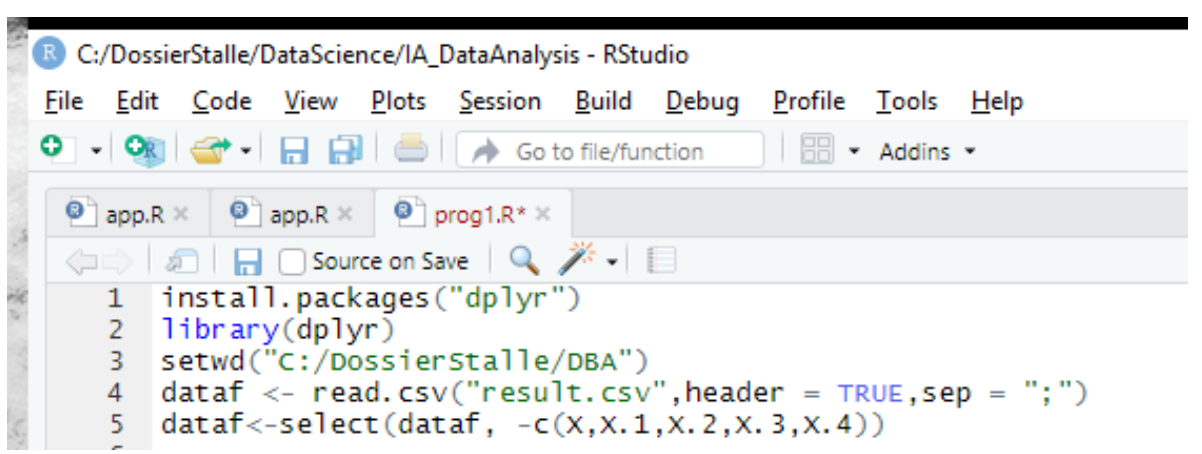

A quick summary of Q1 variable (as per the figure below) shows that respondents have been working in healthcare services in various areas. Among the 72 people interviewed, 23 representing 32\% respondents have been working in Hospitals as physicians, or healthcare professional or administrative staff, and $30(42 \%)$ working as pharmacists. The rest of the respondents also have been working in other medical or paramedical professions.

\begin{tabular}{|c|c|c|c|c|c|}
\hline AUDIOLOGIST & CLINICS & DENTIST & DENTUROLOGIST & ergotherapist & HOSPITAL \\
\hline 1 & 3 & 5 & 1 & 1 & 23 \\
\hline LABORATORY & MASSOTHERAPY & OPTEMETRIST & OPTOMETRIST & OSTEOPATH & PHARMACY \\
\hline 1 & 1 & 0 & 2 & 2 & 30 \\
\hline $\begin{array}{r}\text { PHYSIO } \\
2 \\
100 * t a b l e(d)\end{array}$ & taf $\$ Q 1) / \operatorname{sum}(t a$ & $e($ dataf \$Q1) & & & \\
\hline AUDIOLOGIST & $\begin{array}{l}\text { CLINICS } \\
466667\end{array}$ & $\begin{array}{l}\text { DENTIST } \\
\end{array}$ & DENTUROLOGIST & ergother apist & $\begin{array}{l}\text { HOSPITAL } \\
31 \text { M }\end{array}$ \\
\hline LABORATORY & MASSOTHERAPY & OPTEMETRIST & OPTOMETRIST & OSTEOPATH & PHARMACY \\
\hline 1. 388889 & 1. 388889 & 0.000000 & 2.777778 & 2.777778 & 41.666667 \\
\hline $\begin{array}{r}\text { PHYSIO } \\
2.777778\end{array}$ & & & & & \\
\hline
\end{tabular}

The analysis of variable Q3 points out the fact that most of the respondents do not have an IT background. Only four respondents have a college degree or a certificate in IT and IS. In terms of years of experience in healthcare, the summary of Q4 variable shows that 36 respondents $(50 \%)$ have more than 11 years of experience, 16 respondents have years of experience between 7 to 10 years (representing $22 \%$ of respondents), and 11 respondents years of experience between 3 to 6 years (representing 15\% of respondents). Young people in the profession, with less than 3 years of experience, represent $12.5 \%$ of the respondents. The summary of Q5 variable related to years of experience in IT/IS project reveals that $64 \%$ of respondents have less than 3 years of experience in IT/IS projects, $15 \%$ with 3 to 6 years of experience, and almost $21 \%$ have more than 6 years of experience as the main actors in IT/IS projects. 
The next section consists of analyzing and testing the research statement of the study based on the answers provided by respondents. We first grouped variables (questions) per research statement, so that we can easily analyze research statements based on the responses provided by respondents (see Table 1 below).

Table 1. Research statement associated with elements of questionnaire

\begin{tabular}{|c|c|}
\hline Research Statement & Related Questions \\
\hline \multirow{5}{*}{$\begin{array}{l}\text { Stakeholders in healthcare } \\
\text { organizations perceive EA as a tool of } \\
\text { planning IT/IS project }\end{array}$} & $\begin{array}{l}\text { Q6- EA should be used as a tool of planning } \\
\text { in IT/IS projects. }\end{array}$ \\
\hline & $\begin{array}{l}\text { Q8: A primary goal of EA in IT/IS projects } \\
\text { is to improve the outcomes from the use of } \\
\text { technology. }\end{array}$ \\
\hline & $\begin{array}{l}\text { Q10: IT/IS projects supporting the } \\
\text { treatment of critical diseases, such as cancer, } \\
\text { should have a higher priority than projects to } \\
\text { support simple injuries. }\end{array}$ \\
\hline & $\begin{array}{l}\text { Q18: EA should identify and analyze the } \\
\text { execution of change toward desired business } \\
\text { vision and outcomes. }\end{array}$ \\
\hline & $\begin{array}{l}\text { Q9: A primary goal of EA in IT/IS projects } \\
\text { is to reduce the costs of healthcare activities. }\end{array}$ \\
\hline \multirow{4}{*}{$\begin{array}{l}\text { Stakeholders in healthcare } \\
\text { organizations perceive EA as a tool of } \\
\text { integrating IT solutions }\end{array}$} & $\begin{array}{l}\text { Q8: A primary goal of EA in IT/IS projects } \\
\text { is to improve the outcomes from the use of } \\
\text { technology. }\end{array}$ \\
\hline & $\begin{array}{l}\text { Q11: Each IT/IS project in EA document } \\
\text { should demonstrate its integration with other } \\
\text { existing solutions. }\end{array}$ \\
\hline & $\begin{array}{l}\text { Q12: An IT/IS project with no interaction } \\
\text { on existing solutions should be excluded in an } \\
\text { EA document. }\end{array}$ \\
\hline & $\begin{array}{l}\text { Q13: An IT/IS project with interactions on } \\
\text { existing solutions should be included in EA } \\
\text { document even if it has a limited impact on } \\
\text { service quality. }\end{array}$ \\
\hline \multirow{3}{*}{$\begin{array}{l}\text { Stakeholders in healthcare } \\
\text { organizations consider EA as a tool to } \\
\text { break down organizational silos }\end{array}$} & $\begin{array}{l}\text { Q14: EA is a tool that can help break down } \\
\text { administrative silos within an organization. }\end{array}$ \\
\hline & $\begin{array}{l}\text { Q15: EA is a tool that can help create } \\
\text { synergy between managers of different } \\
\text { departments in an organization. }\end{array}$ \\
\hline & $\begin{array}{l}\text { Q16: EA encourages department heads to } \\
\text { compete intensely to be the owners of business } \\
\text { processes in IT/IS projects. }\end{array}$ \\
\hline $\begin{array}{c}\text { Stakeholders in healthcare } \\
\text { organizations perceive EA as a tool of }\end{array}$ & $\begin{array}{l}\text { Q6: EA should be used as a tool of planning } \\
\text { in IT/IS projects. }\end{array}$ \\
\hline
\end{tabular}




\begin{tabular}{|c|c|}
\hline \multirow[t]{4}{*}{ digital transformation. } & $\begin{array}{l}\text { Q8: A primary goal of EA in IT/IS projects } \\
\text { is to improve the outcomes from the use of } \\
\text { technology. }\end{array}$ \\
\hline & $\begin{array}{l}\text { Q16: EA encourages department heads to } \\
\text { compete intensely to be the owners of business } \\
\text { processes in IT/IS projects. }\end{array}$ \\
\hline & $\begin{array}{l}\text { Q18: EA should identify and analyze the } \\
\text { execution of change toward desired business } \\
\text { vision and outcomes. }\end{array}$ \\
\hline & $\begin{array}{l}\text { Q19: EA delivers value by presenting } \\
\text { business and IT leaders with signature-ready } \\
\text { recommendations for adjusting policies and } \\
\text { projects to achieve target business outcomes. }\end{array}$ \\
\hline \multirow{4}{*}{$\begin{array}{l}\text { Stakeholders in healthcare } \\
\text { organizations consider EA as a tool for } \\
\text { proactively and holistically leading } \\
\text { enterprise responses to disruptive } \\
\text { forces. }\end{array}$} & $\begin{array}{l}\text { Q6: EA should be used as a tool of planning } \\
\text { in IT/IS projects. }\end{array}$ \\
\hline & $\begin{array}{l}\text { Q7: A primary goal of EA in IT/IS projects } \\
\text { is to improve the well-being of the patient } \\
\text { population. }\end{array}$ \\
\hline & $\begin{array}{l}\text { Q8: A primary goal of EA in IT/IS projects } \\
\text { is to improve the outcomes from the use of } \\
\text { technology. }\end{array}$ \\
\hline & $\begin{array}{l}\text { Q19: EA delivers value by presenting } \\
\text { business and IT leaders with signature-ready } \\
\text { recommendations for adjusting policies and } \\
\text { projects to achieve target business outcomes. }\end{array}$ \\
\hline $\begin{array}{l}\text { Stakeholders in healthcare } \\
\text { organizations consider EA as the process } \\
\text { for translating business vision and } \\
\text { strategy into effective enterprise change. }\end{array}$ & $\begin{array}{l}\text { Q18: EA should identify and analyze the } \\
\text { execution of change toward desired business } \\
\text { vision and outcomes. }\end{array}$ \\
\hline
\end{tabular}

\section{Analysis of Research Statement 1}

"Stakeholders in healthcare organizations perceive EA as a tool of planning IT/IS project"

A part of IT/IS planning and management of IT/IS projects consists of managing outputs of projects and ensuring their alignment with the business objectives. The outcomes of projects have to improve the core objectives of the organization, which can be healthcare cost reduction, prioritizing tools for treating critical disease. The variables Q6, Q8, Q9, and Q18 of the dataset are identified as the ones that help to analyze and test this research statement.

\section{Analysis of Q6 Variable}


The summary of the Q6 variable gives 58\% of respondents who agree or strongly agree that EA should be used as a tool of planning in IT/IS projects. Although $42 \%$ provided a neutral answer, it appears that there is no respondent who disagrees with the role of EA for supporting the planning of IT/IS projects.

$>$ summary (dataf\$Q6) \#Number

A N SA

323010

> 100*table (dataf\$Q6)/sum(table(dataf\$Q6)) \#-- Pourcentage

\section{A N SA \\ $44.44444 \quad 41.66667 \quad 13.88889$ \\ Analysis of Q8 Variable}

$51 \%$ of respondents agree that EA has an objective of improving the outcomes from the use of technology, $23.6 \%$ strongly agree and only $1.3 \%$ of respondents disagree with the objective of EA to improve the outcomes from the use of technology.

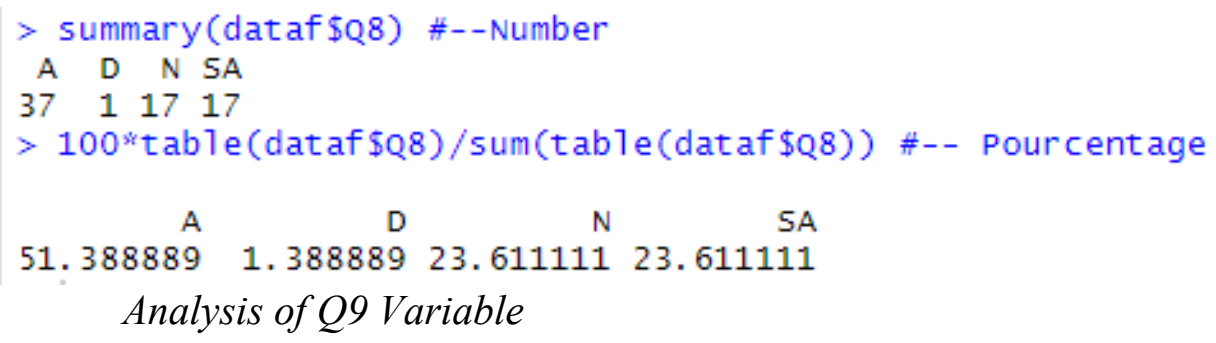

Almost $60 \%$ of the respondents support the idea that a primary goal of EA in IT/IS projects is to reduce the costs of healthcare activities. Only $4 \%$ disagree, and $36 \%$ of respondents preferred to be neutral on that question.

$>$ summary (dataf\$Q9) \#--Number

A D N SA

$\begin{array}{llll}28 & 3 & 26 & 15\end{array}$

$>100 *$ table (dataf\$Q9)/sum(table(dataf\$Q9)) \#-- Pourcentage

\section{A D N N SA \\ $38.888889 \quad 4.166667 \quad 36.11111120 .833333$ \\ Analysis of $Q 18$ Variable}

$78 \%$ of respondents were comfortable to support the idea that EA should identify and analyze the execution of change toward desired business vision and outcomes. No respondent disagrees with that point of view although $22 \%$ preferred to be neutral. 


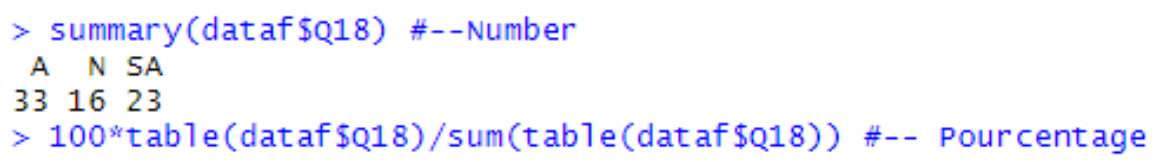

The results on Q6, Q8, Q9, and Q18 variables analysis showed that, excluding those who provided a neutral answer, only less than 5\% disagree in each question. Based on these results, the research statement that "Stakeholders in healthcare organizations perceive EA as a tool of planning IT/IS projects" could be considered as positive. We interviewed subject matter experts in order to compare the outputs of data analysis with experts' opinions. Dr. Cort Coghill (Expert 1) said that EA can be considered as a tool of project planning only in the context of helping with risk and resource alignment. He also states that it is important that EA should not be subjugated as a Project Management sub-skill. EA practice also supports strategic planning, knowledge management programs, etc. So, according to Expert 1, EA supports project planning, but it is not a tool only for project planning. Another expert we met, Dr. Douglas M. Brown (Expert 2), also agrees that EA helps with project planning. He said that we cannot plan effectively if we do not understand the business and how its products are constructed, and where the company is going (vision). A third expert we interviewed, Roger Evernden, TEdx and Keynote Speaker (Expert 3), perceives EA as a planning tool in the sense that it is about managing largescale, systemic, complex change, and to do that we need well-planned projects. He also argued that EA provides a holistic context for the detail provided by project plans. This is why it is important to have EA roadmaps at multiple levels - at the high-level and the strategic end to provide an umbrella over many lower level EA project roadmaps. There should also be an EA roadmap for every project. The expert opinions matched with the responses obtained from the quantitative data.

\section{Analysis of Research Statement 2}

"Stakeholders in healthcare organizations perceive EA as a tool of integrating IT solutions."

The integrating of IT/IS solutions is also determined by the improving of the outcomes from the use of technology. The document that leads the roadmap of IT/IS projects is a source showing the integration of projects, how they interact to support business needs. In case a project does not demonstrate an integration with other solutions, there should not be a reason to keep it maintained in the document. The variables Q8, Q11, Q12, and Q13 are those used to evaluate the goal of EA to support the integration of IT/IS 
solutions. As we already analyzed the Q8 variable in the previous section, we have focused on variables Q11, Q12, and Q13.

\section{Analysis of Q11 Variable}

Only three respondents disagree with the goal of the EA document to demonstrate the integration of IT/IS projects with existing solutions. A total of $56 \%$ of respondents agree (actually $17 \%$ strongly agree) and $40 \%$ was of a neutral point of view on that question.

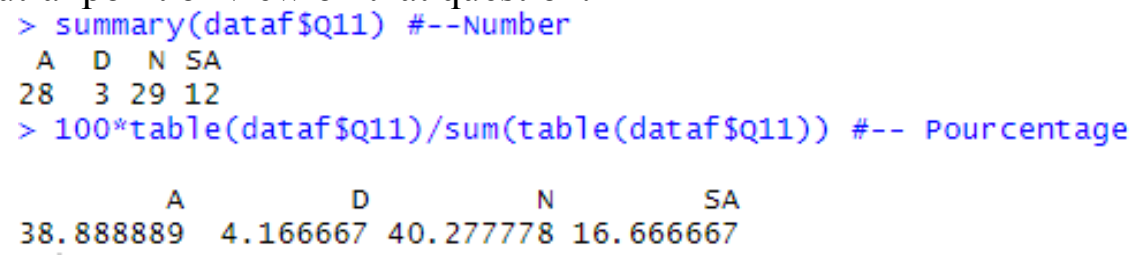

Analysis of Q12 Variable

Concerning the point that IT/IS projects with no interaction on existing solutions should be excluded in an EA document, less than 50\% (only 29 respondents) agree. We also have $44 \%$ of neutral responses and $15 \%$ of respondents who disagree.

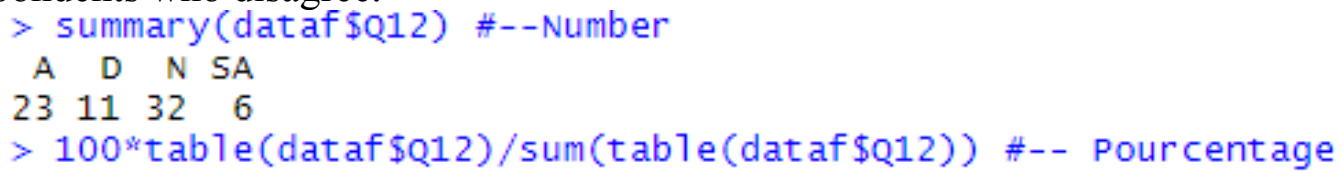

Less than $50 \%$ of respondents agree that an IT/IS project with interactions on existing solutions should be included in an EA document even if it has a limited impact on service quality. A total of $13.9 \%$ disagree and $37.5 \%$ of respondents gave neutral responses.

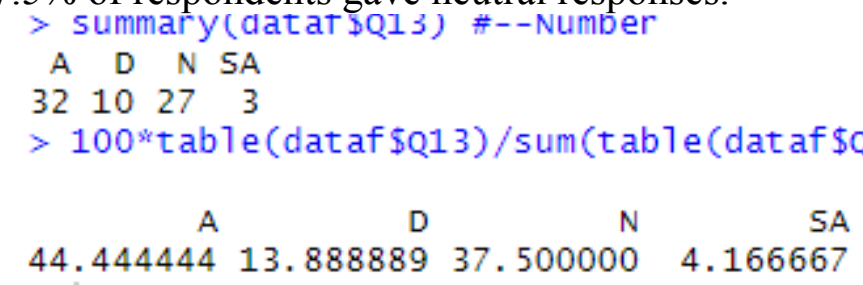

The low rate of respondents who agree to include a project with no interaction on existing solutions (Q12 variable) could lead to state that stakeholders consider EA as a tool for integrating IT solutions. There is no reason to include a project in an EA document if it doesn't integrate with existing solutions. In addition, the analysis of the Q11 variable (EA 
document should demonstrate its integration with other existing solutions) results show only 3 respondents who disagree. The analysis of Q13 variables reveals a low rate of respondents who agree to include in EA document a project with interaction on existing solutions if the project does not have an impact on service quality.

As per results of data analysis, integration seems not to be the main point to consider when we include a project in an EA document in healthcare organizations, but on the impact of the project on quality of service provided by the organization. An interview with experts to compare outputs of data analysis with experts' point of view revealed that EA documents do not only consider integration as the main characteristic when we have to include a project in the EA document. According to Expert 1, an enterprise by its nature is a family of systems. Thus, no aspect of a system can be changed (i.e., reassignment of responsibilities to a new role or changing a computer screen) without impacting another part of the organization. So, to state that integration of systems is the start point is suggesting that there are elements of the enterprise that do participate in the development of the organization. This is a patently wrong understanding of system dynamics and the concept of enterprises as open systems and which is subject to emergent behavior. Expert 2 thinks that the whole point of EA is about integration. Expert 3 argues that integration of systems is just one of the outcomes that EA might be used for. The important point is to define the required outcomes and expectations of shareholders. EA then can be used to manage the strategic vectors and ensure that every project helps contribute to the overall EA direction.

\section{Analysis of Research Statement 3}

"Stakeholders in healthcare organizations consider EA as a tool to break down organizational silos"

Breaking down silos is a way that helps people work together and support each other based on the interest of reaching the common objectives of the organization. An organization relies on a set of processes and each process has a lead. However, no process can work alone, but it needs inputs from other processes and supplies other processes with its outputs. So, breaking down silos will help process owners to support each other by playing the role of a leader in their respective process. Here, we identified variables Q14, Q15, and Q16 to analyze this research statement.

\section{Analysis of Q14 Variable}

A total of $70 \%$ of respondents agree on the goal of EA to help break down administrative silos within an organization. Only 3\% disagree and 26\% are neutral. 


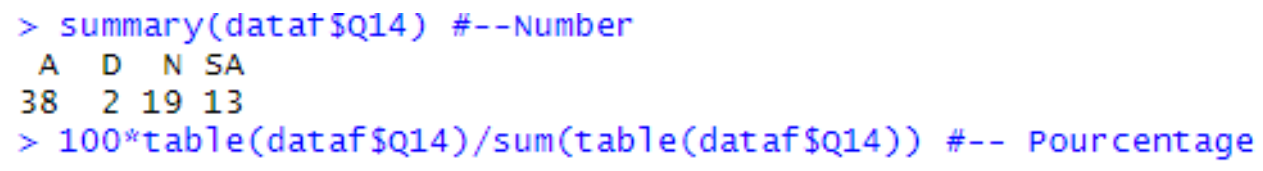

$\begin{array}{rrrr}\text { A } & \text { D } & \text { N } & \text { SA } \\ 52.777778 & 2.777778 & 26.388889 & 18.055556\end{array}$

Analysis of $Q 15$ Variable

A total of $75 \%$ of respondents agreed that EA is a tool that can help create synergy between managers of different departments in an organization. No respondent disagreed.

$>$ summary(dataf\$Q15) \#--Number

A N SA

401814

$>100 *$ table(dataf\$Q15)/sum(table(dataf\$Q15)) \#-- Pourcentage

\section{$\begin{array}{rrr}\text { A } & \text { N } & \text { SA } \\ 55.55556 & 25.00000 & 19.44444\end{array}$}

\section{Analysis of Q16 Variable}

Although we noted a high rate of respondents (42\%) with a neutral opinion on that question, the analysis of Q16 variable shows that only 1 respondent disagrees with the fact that EA encourages department heads to compete intensely to be the owners of business processes in IT/IS projects.

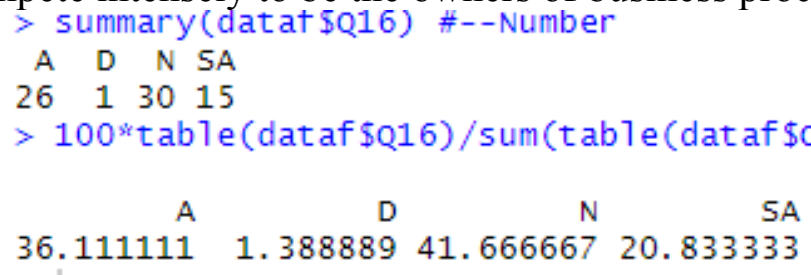

\section{A $\quad$ D $\quad N \quad$ SA \\ $\begin{array}{lllll}36.111111 & 1.388889 & 41.666667 & 20.833333\end{array}$}

The analysis of the three variables (Q14, Q15 and Q16), as presented above and which is based on the answers of respondents, shows that the research statement of "Stakeholders in healthcare organizations consider EA as a tool to break down organizational silos" would be considered as true. We asked three experts about the capability of EA to break down silo. The opinion of Expert 1 is that EA absolutely breaks down silos as it provides a holistic, rather than a partisan (silo) perspective. This was similar to a comment provided by one respondent working in a hospital when he was answering the questionnaire. The expert also revealed that stakeholders' management, describing concerns in terms of how the architecture contributes to causing concerns, helps break down silos. Expert 2 stated that EA helps break down silos only when EA is understood as a holistic enterprise planning tool and not a subdomain or practice of IT. He also said that, presently, a good deal of EA practitioners falsely subscribes to the concept of EA as an IT planning tool/construct. Expert 3 opines that EA can 
help break down silos as it can show where organizational groupings share commonalities.

\section{Analysis of Research Statement 4}

"Stakeholders in healthcare organizations perceive EA as a tool of digital transformation."

We considered variables Q6, Q8, Q16, Q18, and Q19 to analyze this research statement related to digital transformation. In fact, digital transformation is the profound transformation of business and organizational activities, processes, competencies, and models to leverage the changes and opportunities of a mix of digital technologies and their accelerating impact across society in a strategic and prioritized way in the present and future. As we already saw on research statement 1 analysis, the variables Q6, Q8, and Q18 received a very high rate of respondents who agree or strongly agree. The analysis of the Q19 variable also shows that no respondent disagrees. This could imply that stakeholders in healthcare organizations also perceive EA as a tool of digital transformation. A few respondents suggested that digital transformation is a new lever that will help organizations to take competitive advantage and, hence, it needs to be supported by EA.

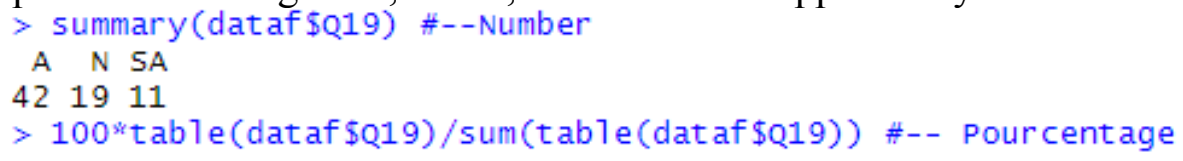

We also asked the experts if they agree that EA is an effective tool of digital transformation. Expert 1 said it depends on many factors. He argued that the vast majority of digital transformation is viewed as an exercise in technology and not a transformation in an organization's business model. If we mean digital transformation as a part of business model transformation and considering the range of factors such as culture, content and tools, the answer is yes. If we mean digital transformation as an exercise in technology transformation, the answer is no because that is IT Architecture and not EA. Expert 2 opines that EA can be and should be an effective tool of digital transformation. Often it is not, and may even be an obstacle, if the EA staff do not understand the idea of "fit for purpose". Expert 3 agreed that EA is an effective tool of digital transformation like any other type of transformation. 


\section{Analysis of Research Statement 5}

"Stakeholders in healthcare organizations consider EA as a tool for proactively and holistically leading enterprise responses to disruptive forces."

To proactively and holistically lead enterprise to disruptive forces, a company needs to manage projects in a well-organized framework, aiming to improve outcomes related to the use of technology. Leaders need to be proactive and provide recommendations to anticipate bad situations that can disrupt the functioning of the organization. To analyze this research statement, we chose variables Q6, Q8, and Q19. Variables Q6 and Q8 on analysis of research statement 1 gave the results that all respondents in Q6 agree that EA should be used as a tool of planning in IT/IS projects. For variable Q8, only one respondent disagrees that a primary goal of EA in IT/IS projects is to improve the outcomes from the use of technology. The analysis of answers provided in variable Q19 (as below) also shows that no respondent disagrees that EA delivers value by presenting business and IT leaders with signature-ready recommendations for adjusting policies and projects to achieve target business outcomes.

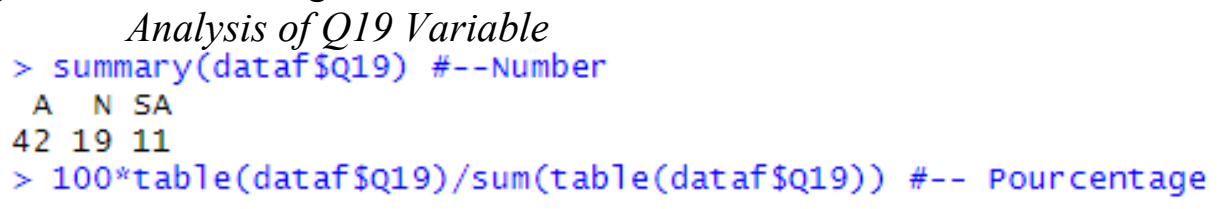

$\begin{array}{llll}58.33333 & 26.38889 & 15.27778\end{array}$

With a high rate of respondents who agree on questions related to Q6, Q8 and Q19 variables, this research statement can be considered as positive. According to Expert 1,2 and 3, EA can help enterprises to proactively and holistically respond to disruptive forces. They assert that EA is indeed a holistic enterprise planning tool as it takes into consideration the organization and its environment. As such, it helps the organization to appropriately and timely respond to disruptive forces.

Analysis of Research Statement 6

"Stakeholders in healthcare organizations consider EA as the process for translating business vision and strategy into effective enterprise change."

Translating business vision and strategy into effective enterprise change needs to be proactive by taking into cognizance the opportunities and the constraints of the business environment. For this research statement, we identified the Q18 variable, which is related to the question asked to respondents - EA should identify and analyze the execution of change toward desired business vision and outcomes - as the best fit for analysis. 
As we can see on the results above, 56 respondents agree or strongly agree. There is no respondent who disagreed. Without the neutral answers on that question, we have $100 \%$ of respondents in favor that EA should identify and analyze the execution of change toward desired business vision and outcomes. Some of them provided additional comments supporting this perception.

We questioned experts to know their opinion about the characteristic of EA to identify and analyze the execution of change toward desired business vision and outcomes, and if they are using EA for this purpose. Expert 1 answered by agreeing that anything different is a sub domain of EA such as Business, IS or Data Architecture. EA is concerned with enterprise outcomes. Expert 2 also agrees with the fact that we cannot effectively make a good plan if we do not understand the business environment and factors that drive the business changes within organizations. EA through its subdomains support should identify and analyze the execution of change toward desired business vision and outcomes. Expert 3 agrees and points out the fact that change will happen anyway. Thus, we can choose whether we want to manage and direct it or not. EA is one of the best tools if you choose to manage and direct change because it genuinely takes into account all views and viewpoints and then works out how to gain synergies between them towards the common vision and outcomes.

\section{Summary of Findings}

This study aims to explore and analyze the perceptions of stakeholders in healthcare organizations in Canada on how they developed their own model of EA to improve managerial decision making and align business activities and IT within the enterprise. Below are the summaries of the key findings:

- Stakeholders in Healthcare organizations perceive EA as a tool of planning IT/IS projects. In fact, data analysis from questionnaire responses, coupled with experts' interview, showed almost 95\% of participants who agreed to the positive impact of EA on IT/IS projects planning. It also shows the capability of EA to improve the outcomes of technologies as it provides a framework in which the use of technologies must be aligned with business strategy and objectives, and also aligned with business processes. Moreover, the parameter of cost (healthcare costs) which is an essential element in project management was highly approved by participants as optimized when EA is involved in the project management.

- Stakeholders in healthcare organizations do not necessarily perceive EA as a tool of integrating IT solutions. Indeed, stating that EA is a tool for integrating IT solutions means that all IT/IS projects must be 
mentioned in the EA document, demonstrating their integration to support business challenges and highlighting a real impact on quality of services provided to patients. As per stakeholders answers, integration of IT/IS is often absent in EA documents developed by professionals. However, experts in the field of EA agreed that EA documents do not only consider integration as the main characteristic when we must include a project in the EA document.

- Stakeholders in healthcare organizations consider EA as a tool to break down organizational silos. More than $90 \%$ of respondents agreed on the added value of EA in bringing stakeholders around the same business objectives, sharing the same vision, and supporting each other in reaching the expected results. Results of the research study show that EA absolutely breaks down silos as it provides a holistic, rather than a partisan (silo) perspective. EA is understood as a holistic enterprise planning tool and not a subdomain or practice of IT.

- Stakeholders in healthcare organizations perceive EA as a tool of digital transformation. $90 \%$ of stakeholders perceive EA as a tool to support the digital transformation within organizations. Indeed, according to respondents, digital transformation consists of transforming business processes by bringing technologies to support activities in the way they are optimized to create more value by reducing time and space which are no longer a problem for organization today because of new technologies. Any changes in organizations must be managed as projects. In that case, as we saw in research statement 1 that EA is a tool supporting IT/IS planning, it also supports changes which can be related to digital transformations. The positive testing was comforted by an expert's opinion we met who argued that if we mean digital transformation as a part of business model transformation and considering the range of factors such as culture, content and tools, it is right to consider EA as a tool of digital transformation.

- Stakeholders in healthcare organizations consider EA as a tool for proactively and holistically leading enterprise responses to disruptive forces. Results showed $95 \%$ of respondents who agreed that EA provides a framework that helps to gather all elements and factors (internal and external), necessary to proactively manage potential organizational issues. Indeed, the process of implementing the framework of EA involves questioning about business strategy and objectives, business processes, IS and technology. By doing so, practitioners will identify factors that would influence the functioning 
of the organization and actions plan will be developed to tackle the situation.

- Stakeholders in healthcare organizations consider EA as the process for translating business vision and strategy into effective enterprise change. In fact, $100 \%$ of respondents agreed with the capability of EA to translate the business vision and strategy to a set of actions leading to changes within the organization. This was also approved by experts we interviewed who provided arguments to support the statement.

\section{Conclusion}

The study aimed to explore the perceptions of stakeholders in healthcare organizations in Canada on how they developed Enterprise Architecture (EA) to improve managerial decision making and align business activities and Information Technology (IT). This study is particularly relevant considering the importance of healthcare, the concerns surrounding the rising cost of healthcare delivery, and the role of technology in achieving efficient healthcare delivery. Also, there is growing concern in the misalignment between the cost of procuring and implementing IT and technology projects in healthcare organizations and achieving the desired results. The findings of this research show that EA can help bring about the desired results in healthcare organizations as it is the right tool for planning IT/IS projects; developing digital transformation, bringing business objectives and strategy into life, and removing silos that exist within the organization. Furthermore, the findings of this research is very significant as no previous study as far as we know explored the perceptions of medical practitioners and other employees within healthcare organizations in Canada on how they developed EA to improve managerial decision making and align business activities and IT.

As much as the findings of this research remain very significant, there are some limitations in the research process. The research study has a limitation in stakeholders sampling that needs to be highlighted. Stakeholders sampling of the study did not include government personnel such as healthcare decision makers in government. We know that those people have a significant influence on decisions made in the healthcare sector, hence would have an impact on the results of this study. Also the researchers would have wished to send out questionnaires to more participants and interviewed more participants beyond the three experts. However, these were hampered due to funding and time constraints.

We would like to recommend a few areas for future research. It is recommended that future researchers should measure the impact of stakeholders' experience on their perceptions of EA. The idea would be to 
test if stakeholders who have been familiar with EA are more likely to encourage the integration of EA in the framework of governance within healthcare organizations. Another research study topic could be to test the impact of healthcare organizations size on the stakeholders "perceptions. Another area for next research study could be to analyze the correlation between size of healthcare organizations and the perception of stakeholders on EA. The researcher could study if stakeholders in large healthcare organizations are more likely to perceive the importance of EA than stakeholders working in small healthcare organizations.

\section{References}

Abunadi, I. (2019). Enterprise architecture best practices in large corporations. Information, 10(10), 293.

Aceto, G., Persico, V., \& Pescapé, A. (2018). The role of Information and Communication Technologies in healthcare: taxonomies, perspectives, and challenges. Journal of Network and Computer Applications, 107, 125-154.

Aguinis, H. (2019). Performance management for dummies. John Wiley \& Sons.

Ahlemann, F., Legner, C., \& Lux, J. (2021). A resource-based perspective of value generation through enterprise architecture management. Information \& Management, 58(1), 103266.

Ahmadi, H., Nilashi, M., Shahmoradi, L., \& Ibrahim, O. (2017). Hospital Information System adoption: Expert perspectives on an adoption framework for Malaysian public hospitals. Computers in Human Behavior, 67, 161-189.

Almeida, F. (2018). Strategies to perform a mixed methods study. European Journal of Education Studies.

Alotaibi, Y., \& Liu, F. (2017). Survey of business process management: challenges and solutions. Enterprise Information Systems, 11(8), 1119-1153.

Ashdown, L. (2018). Performance Management: A practical introduction. Kogan Page Publishers.

Aspers, P., \& Corte, U. (2019). What is qualitative in qualitative research. Qualitative sociology, 42(2), 139-160.

Banaeianjahromi, N., \& Smolander, K. (2019). Lack of communication and collaboration in enterprise architecture development. Information Systems Frontiers, 21(4), 877-908. 
Bhattacharya, P. (2018). Aligning enterprise systems capabilities with business strategy: an extension of the strategic alignment model (SAM) using enterprise architecture. Procedia computer science, 138, 655-662.

Bokhour, B. G., Fix, G. M., Mueller, N. M., Barker, A. M., Lavela, S. L., Hill, J. N., ... \& Lukas, C. V. (2018). How can healthcare organizations implement patient-centered care? Examining a largescale cultural transformation. BMC health services research, 18(1), 111.

Bradshaw, C., Atkinson, S., \& Doody, O. (2017). Employing a qualitative description approach in health care research. Global qualitative nursing research, 4, 2333393617742282.

Chafe, R. (2017). The value of qualitative description in health services and policy research. Healthcare Policy, 12(3), 12.

Cleary, M., Horsfall, J., \& Hayter, M. (2014). Data collection and sampling in qualitative research: does size matter?. Journal of advanced nursing, 473-475.

Dang, D. D., \& Pekkola, S. (2017). Systematic Literature Review on Enterprise Architecture in the Public Sector. Electronic Journal of eGovernment, 15(2)

Dimitropoulos, P. E. (2017). Performance management in healthcare organizations: concept and practicum. In GeNeDis 2016 (pp. 11-19). Springer, Cham.

Du Plessis, J. J., Hargovan, A., \& Harris, J. (2018). Principles of contemporary corporate governance. Cambridge University Press

Esfahani, A. A., Ahmadi, H., Nilashi, M., Alizadeh, M., Bashiri, A., Farajzadeh, M. A., ... \& Rasouli, H. R. (2018). An evaluation model for the implementation of hospital information system in public hospitals using multi-criteria-decision-making (MCDM) approaches. International Journal of Engineering and Technology (UAE), 7(1), 118.

Foorthuis, R., van Steenbergen, M., Mushkudiani, N., Bruls, W., Brinkkemper, S., \& Bos, R. (2020). On course, but not there yet: Enterprise architecture conformance and benefits in systems development. arXiv preprint arXiv:2008.11026.

Gampfer, F., Jürgens, A., Müller, M., \& Buchkremer, R. (2018). Past, current and future trends in enterprise architecture-A view beyond the horizon. Computers in Industry, 100, 70-84.

Gerber, A., le Roux, P., Kearney, C., \& van der Merwe, A. (2020, April). The Zachman Framework for Enterprise Architecture: An Explanatory IS Theory. In Conference on e-Business, e-Services and e-Society (pp. 383-396). Springer, Cham. 
Greer, C. R., Lusch, R. F., \& Hitt, M. A. (2017). A service perspective for human capital resources: A critical base for strategy implementation. Academy of Management Perspectives, 31(2), 137-158.

Gorkhali, A., \& Xu, L. D. (2017). Enterprise architecture: a literature review. Journal of Industrial Integration and Management, 2(02), 1750009

Guha, S., \& Kumar, S. (2018). Emergence of big data research in operations management, information systems, and healthcare: Past contributions and future roadmap. Production and Operations Management, 27(9), 1724-1735.

Hammarberg, K. et al. (2016). Qualitative research methods: When to use them and how to judge them. Human reproduction (Oxford, England). 31. 10.1093/humrep/dev334.

Harlie, M., Rajiani, I., \& Abbas, E. W. (2019). Managing information systems by integrating information systems success model and the unified theory of acceptance and usage of technology. Polish Journal of Management Studies, 20.

Harmon, P. (2019). Business Process Change: A Business Process Management Guide for Managers, Morgan Kaufmann, 2019

Hazen, B. T., Bradley, R. V., Bell, J. E., In, J., \& Byrd, T. A. (2017). Enterprise architecture: A competence-based approach to achieving agility and firm performance. International Journal of Production Economics, 193, 566-577.

Hernandez, S. R., O'connor, S. J., \& Meese, K. A. (2018). Global efforts to professionalize the healthcare management workforce: the role of competencies. The Journal of Health Administration Education, 35(2), 157.

Herdjiono, I., \& Sari, I. M. (2017). The effect of corporate governance on the performance of a company. Some empirical findings from Indonesia. Journal of Management and Business Administration. Central Europe, 25(1), 33-52.

Hwabamungu, B., Brown, I., \& Williams, Q. (2018). Stakeholder influence in public sector information systems strategy implementation-The case of public hospitals in South Africa. International journal of medical informatics, 109, 39-48.

Ilin, I., Levina, A., Lepekhin, A., \& Kalyazina, S. (2018, December). Business requirements to the IT architecture: a case of a healthcare organization. In Energy Management of Municipal Transportation Facilities and Transport (pp. 287-294). Springer, Cham 
Islam, M. M., Poly, T. N., \& Li, Y. C. J. (2018). Recent advancement of clinical information systems: Opportunities and challenges. Yearbook of medical informatics, 27(1), 83.

Jonnagaddala, J., Guo, G. N., Batongbacal, S., Marcelo, A., \& Liaw, S. T. (2020). Adoption of enterprise architecture for healthcare in AeHIN member countries. BMJ health \& care informatics, 27(1).

Juiz, C., Gomez, B., \& Rosenmöller, M. (2017, October). e-Health should be governed as other assets in healthcare organizations. In 2017 IEEE 19th International Conference on e-Health Networking, Applications and Services (Healthcom)(pp. 1-6). IEEE.

Júnior, S. H. D. L., Silva, F. Í. C., Albuquerque, G. S. G., de Medeiros, F. P. A., \& Lira, H. B. (2020). Enterprise Architecture in Healthcare Systems: A systematic literature review. arXiv preprint arXiv:2007.06767.

Jusuf, M. B., \& Kurnia, S. (2017, January). Understanding the benefits and success factors of enterprise architecture. In Proceedings of the 50th Hawaii International Conference on System Sciences.

Kabeyi, M. (2019). Organizational strategic planning, implementation and evaluation with analysis of challenges and benefits. International Journal of Applied Research and Studies, 5(6), 27-32

Kasemsap K. et al. (2018). The Role of Information System Within Enterprise Architecture and Their Impact on Business Performance, Global Business Expansion: Concepts, Methodologies, Tools, and Applications

Kernick, D. (2018). Complexity and healthcare organization: A view from the street. CRC Press.

Kitsios, F. \& Kamariotou, M. (2017). Enterprise Architecture Management for Business Strategy Modelling. Conference: BAM 2017

Kitsios, F., \& Kamariotou, M. (2019). Business strategy modelling based on enterprise architecture: A state of the art review. Business Process Management Journal.

Kotusev, S. (2017). Enterprise architecture: what did we study?. International Journal of Cooperative Information Systems, 26(04), 1730002.

Kotusev, S. (2018). Enterprise Architecture: A reconceptualization is needed. Pacific Asia Journal of the Association for Information Systems, 10(4), 2.

Knauer, T., Nikiforow, N., \& Wagener, S. (2020). Determinants of information system quality and data quality in management accounting. Journal of Management Control, 1-25. 
Lagsten, J., \& Andersson, A. (2018). Use of information systems in social work-challenges and an agenda for future research. European Journal of Social Work, 21(6), 850-862.

Latham, A. (2017). The Importance Of Strategic Focus. Forbes (https://www.forbes.com/sites/annlatham/2017/11/12/the-importanceof-strategic-focus/\#3553444e 587d)

Laudon, K. C., \& Laudon, J. P. (2000). Management information systems: organization and technology in the networked enterprise. Prentice Hall International,.

Lauvrak, S., Michaelsen, V. K., \& Olsen, D. H. (2017, November). Benefits and Challenges in enterprise architecture management: A case study of the Norwegian labour and welfare administration. In Norsk konferanse for organisasjoners bruk at IT (Vol. 25, No. 1).

Leal, G. D. S. S., Guédria, W., \& Panetto, H. (2019). Interoperability assessment: A systematic literature review. Computers in Industry, 106, 111-132.

Laurenza, E., Quintano, M., Schiavone, F., \& Vrontis, D. (2018). The effect of digital technologies adoption in healthcare industry: a case based analysis. Business process management journal.

Lombardi, R. (2019). Knowledge transfer and organizational performance and business process: past, present and future researches. Business Process Management Journal.

Lopez, F.G. \& Bustos, G. (2019). Integration of Business Process Architectures within Enterprise Architecture Approaches: A Literature Review. Journal Engineering

MacDougall, A., Valley, J.M., \& Yalden, R.M. (2017). The Corporate Governance Review, Seventh Edition: Canada (2017). The law reviews.

Retrieved from https://www.osler.com/en/resources/governance/2017/the-corporategovernance-review-seventh-edition

Madhani, P. M. (2017). Diverse roles of corporate board: Review of various corporate governance theories. The IUP Journal of Corporate Governance, 16(2), 7-28.

Masuda, Y., Zimmermann, A., Viswanathan, M., Bass, M., Nakamura, O., \& Yamamoto, S. (2021). Adaptive Enterprise Architecture for the Digital Healthcare Industry: A Digital Platform for Drug Development. Information, 12(2), 67.

Mcintyre, D., Meheus, F., \& Røttingen, J. A. (2017). What level of domestic government health expenditure should we aspire to for universal health coverage?. Health Economics, Policy and Law, $12(2), 125-137$. 
McKiernan, P. (Ed.) (2017). Historical Evolution of Strategic Management, Volumes I and II (Vol. 1). Taylor \& Francis.

Moons K. et al. (2018). Measuring the logistics performance of internal hospital supply chains - A literature study, ScienceDirect Omega Volume 82, January 2019, Pages 205-217

Neto, V. V. G., Araujo, R., \& dos Santos, R. P. (2017, December). New challenges in the social web: Towards systems-of-information systems ecosystems. In Anais do VIII Workshop sobre Aspectos da Interação Humano-Computador para a Web Social (pp. 1-12). SBC.

Nugroho, H. (2017). Proposed IT Governance at Hospital Based on COBIT 5 Framework. IJAIT (International Journal of Applied Information Technology), 1(01), 52-58

Obeidat, B.Y., Al-Hadidi, A., \& Tarhini, A. (2017). Factors affecting strategy implementation: A case study of pharmaceutical companies in the Middle East. Review of International Business and Strategy

Paley, N. (2019). Timeless Leadership Truths: The Origins and Applications of Business Strategy. CRC Press.

Patri, R. \& Suresh, M. (2017). Factors influencing lean implementation in healthcare organizations: An ISM approach. Journal International Journal of Healthcare Management, Volume 11, 2018 - Issue 1

Patri, R., \& Suresh, M. (2017). Modelling the enablers of agile performance in healthcare organization: a TISM approach. Global Journal of Flexible Systems Management, 18(3), 251-272.

Pérez-Castillo, R., Ruiz, F., \& Piattini, M. (2020). A decision-making support system for Enterprise Architecture Modelling. Decision Support Systems, 131, 113249.

Pickup, L., Lang, A., Atkinson, S., \& Sharples, S. (2018). The dichotomy of the application of a systems approach in UK healthcare the challenges and priorities for implementation. Ergonomics, 61(1), 1525.

Pillai, R., \& Al-Malkawi, H. A. N. (2018). On the relationship between corporate governance and firm performance: Evidence from GCC countries. Research in International Business and Finance, 44, 394410.

Plessius, H., van Steenbergen, M., Slot, R., \& Versendaal, J. (2018). The Enterprise Architecture Value Framework. In ECIS(p. 48).

Olsen, D.H. (2017). Enterprise Architecture management challenges in the Norwegian health sector. Procedia computer science, 121, 637-645.

Rahimi, F., Gøtze, J., \& Møller, C. (2017). Enterprise architecture management: Toward a taxonomy of applications. Communications of the Association for Information Systems, 40(1), 7. 
Rahi, S. (2017). Research design and methods: A systematic review of research paradigms, sampling issues and instruments development. International Journal of Economics \& Management Sciences, 6(2), 1-5.

Rani, P. (2019). Strategy Implementation in Organizations: A Conceptual Overview. Management (18544223), 14(3).

Reddy, S., Allan, S., Coghlan, S., \& Cooper, P. (2020). A governance model for the application of AI in health care. Journal of the American Medical Informatics Association, 27(3), 491-497.

Ridgely, M. S., Duffy, E., Wolf, L., Vaiana, M., Scanlon, D., Buttorff, C., ... \& Damberg, C.L. (2019). Understanding US health systems: using mixed methods to unpack organizational complexity. eGEMs, 7(1).

Ross, D. S., \& Venkatesh, R. (2016). Role of hospital information systems in improving healthcare quality in hospitals. Indian journal of science and technology, 9(26), 1-5.

Saidat, Z., Silva, M., \& Seaman, C. (2019). The relationship between corporate governance and financial performance. Journal of Family Business Management.

Saint-Louis, P., Morency, M. C., \& Lapalme, J. (2019). Examination of explicit definitions of enterprise architecture. International Journal of Engineering Business Management, 11, 1847979019866337.

Sanchez, O. P., \& Terlizzi, M. A. (2017). Cost and time project management success factors for information systems development projects. International Journal of Project Management, 35(8), 16081626.

Saridakis, G., Lai, Y., \& Cooper, C.L. (2017). Exploring the relationship between HRM and firm performance: A meta-analysis of longitudinal studies. Human resource management review, 27(1), 87-96.

Sardo, F., \& Serrasqueiro, Z. (2017). A European empirical study of the relationship between firms' intellectual capital, financial performance and market value. Journal of Intellectual Capital.

Saripalle, R. K. (2019). Fast Health Interoperability Resources (FHIR): current status in the healthcare system. International Journal of EHealth and Medical Communications (IJEHMC), 10(1), 76-93

See, E. J., Alrukhaimi, M., Ashuntantang, G. E., Bello, A. K., BellorinFont, E., Gharbi, M. B., ... \& Johnson, D.W. (2018). Global coverage of health information systems for kidney disease: availability, challenges, and opportunities for development. Kidney international supplements, 8(2), 74-81. 
Shanks, G., Gloet, M., Someh, I. A., Frampton, K., \& Tamm, T. (2018). Achieving benefits with enterprise architecture. The Journal of Strategic Information Systems, 27(2), 139-156.

Sheard, J. (2018). Quantitative data analysis. In Research Methods: Information, Systems, and Contexts, Second Edition (pp. 429-452). Elsevier.

Sligo, J., Gauld, R., Roberts, V., \& Villa, L. (2017). A literature review for large-scale health information system project planning, implementation and evaluation. International journal of medical informatics, 97, 86-97.

Smith, M., \& Bititci, U.S. (2017). Interplay between performance measurement and management, employee engagement and performance. International Journal of Operations \& Production Management.

Szabó, Z., \& Öri, D. (2017, December). Information strategy challenges in the digital era how enterprise architecture management can support strategic IS planning. In 2017 11th International Conference on Software, Knowledge, Information Management and Applications (SKIMA) (pp. 1-8). IEEE

Tanaka, S. A., de Barros, R. M., \& de Souza Mendes, L. (2018, June). A proposal to a framework for governance of ICT aiming at smart cities with a focus on Enterprise architecture. In Proceedings of the XIV Brazilian symposium on information systems (pp. 1-8).

Timm, F., Hacks, S., Thiede, F., \& Hintzpeter, D. (2017). Towards a quality framework for enterprise architecture models. In 5th International Workshop on Quantitative Approaches to Software Quality (QuASoQ 2017) co-located with APSEC 2017, Nanjing, China, December 4, 2017 (Vol. 2017, pp. 14-21). CEUR-WS. org.

Tsoukas, H. (2017). Don't simplify, complexify: From disjunctive to conjunctive theorizing in organization and management studies. Journal of management studies, 54(2), 132-153

Wager, K. A., Lee, F. W., \& Glaser, J. P. (2017). Health care information systems: a practical approach for health care management. John Wiley \& Sons.

Walliman, N. (2017). Research methods: The basics. Routledge.

Zwass, V. (2020, November 2). Information system. Encyclopedia Britannica. https://www.britannica.com/topic/information-system 


\section{Appendix 1}

Appendix 1: Questionnaire

\begin{tabular}{|c|c|c|c|c|}
\hline \multicolumn{5}{|l|}{ Personal Information on Respondent } \\
\hline Name of your organisation (optional) & & & & \\
\hline Name of respondent (optional) & $\underline{-}$ & & & \\
\hline College degree or certification in IT/IS area & es & & $\mathrm{N}$ & \\
\hline Years of Experience in healthcare: $0-2,3-6,7-10,11$ or more. & -2 & - & $-10^{7}$ & $1+$ \\
\hline $\begin{array}{l}\text { Years of Experience with IT/IS projects: } 0-2,3-6,7-10,11 \text { or } \\
\text { more. }\end{array}$ & -2 & - & $-10^{7}$ & \\
\hline $\begin{array}{l}\text { How familiar are you with the concept of enterprise } \\
\text { architecture? (High, Medium, Low, Not familiar) }\end{array}$ & $\mathrm{H}$ & & $\mathrm{L}$ & I \\
\hline \multicolumn{5}{|l|}{ Survey Questions } \\
\hline \multicolumn{5}{|l|}{$\begin{array}{l}\text { For each of the following statements, select SA strongly agree, } \\
\text { A agree, } \mathrm{N} \text { neutral or not applicable, D disagree, or SD strongly } \\
\text { disagree. }\end{array}$} \\
\hline EA should be used as a tool of planning in IT/IS projects. & $\mathrm{A}$ & & $\mathrm{N}$ & I \\
\hline $\begin{array}{l}\text { A primary goal of EA in IT/IS projects is to improve the well- } \\
\text { being of the patient population. }\end{array}$ & $\mathrm{A}$ & & $\mathrm{N}$ & I \\
\hline $\begin{array}{l}\text { A primary goal of EA in IT/IS projects is to improve the } \\
\text { outcomes from the use of technology. }\end{array}$ & $\mathrm{A}$ & & $\mathrm{N}$ & I \\
\hline
\end{tabular}




\begin{tabular}{|c|c|c|c|}
\hline $\begin{array}{l}\text { A primary goal of EA in IT/IS projects is to reduce the costs of } \\
\text { healthcare activities. }\end{array}$ & $\mathrm{A}$ & $\mathrm{N}$ & $\mathrm{D}$ \\
\hline $\begin{array}{l}\text { IT/IS projects supporting the treatment of critical diseases, such } \\
\text { as cancer, should have a higher priority than projects to support } \\
\text { simple injuries. }\end{array}$ & A & $\mathrm{N}$ & $\mathrm{D}$ \\
\hline $\begin{array}{l}\text { Each IT/IS project in EA document should demonstrate its } \\
\text { integration with other existing solutions. }\end{array}$ & A & $\mathrm{N}$ & $\mathrm{D}$ \\
\hline $\begin{array}{l}\text { An IT/IS project with no interaction on existing solutions should } \\
\text { be excluded in an EA document. }\end{array}$ & A & $\mathrm{N}$ & $\mathrm{D}$ \\
\hline $\begin{array}{l}\text { An IT/IS project with interactions on existing solutions should } \\
\text { be included in EA document even if it has a limited impact on } \\
\text { service quality. }\end{array}$ & $\mathrm{A}$ & $\mathrm{N}$ & $\mathrm{D}$ \\
\hline $\begin{array}{l}\text { EA is a tool that can help break down administrative silos within } \\
\text { an organization. }\end{array}$ & A & $\mathrm{N}$ & $\mathrm{D}$ \\
\hline $\begin{array}{l}\text { EA is a tool that can help create synergy between managers of } \\
\text { different departments in an organization. }\end{array}$ & $\mathrm{A}$ & $\mathrm{N}$ & $\mathrm{D}$ \\
\hline $\begin{array}{l}\text { EA encourages department heads to compete intensely to be the } \\
\text { owners of business processes in IT/IS projects. }\end{array}$ & A & $\mathrm{N}$ & $\mathrm{D}$ \\
\hline $\begin{array}{l}\text { Stakeholders without IT/IS background often do not support EA } \\
\text { in IT/IS projects. }\end{array}$ & A & $\mathrm{N}$ & $\mathrm{D}$ \\
\hline $\begin{array}{l}\text { Stakeholders with IT/IS background often encourage EA in } \\
\text { IT/IS projects. }\end{array}$ & A & $\mathrm{N}$ & $\mathrm{D}$ \\
\hline $\begin{array}{l}\text { EA should identify and analyze the execution of change toward } \\
\text { desired business vision and outcomes. }\end{array}$ & A & $\mathrm{N}$ & $\mathrm{D}$ \\
\hline $\begin{array}{l}\text { EA delivers value by presenting business and IT leaders with } \\
\text { signature-ready recommendations for adjusting policies and projects } \\
\text { to achieve target business outcomes. }\end{array}$ & A & $\mathrm{N}$ & $\mathrm{D}$ \\
\hline
\end{tabular}

